
allemande

51-2| 2019

Les Humanités environnementales : circulations et renouvellement des savoirs en France et en Allemagne

\title{
Matthias GEMÄHLICH, Frankreich und der Nürnberger Prozess gegen die Hauptkriegsverbrecher 1945/46
}

Berlin, Peter Lang, 2018, 391 p.

Valéry Pratt

\section{(2) OpenEdition}

Édition électronique

URL : https://journals.openedition.org/allemagne/2088

DOI : $10.4000 /$ allemagne.2088

ISSN : 2605-7913

Éditeur

Société d'études allemandes

Édition imprimée

Date de publication : 10 décembre 2019

Pagination : 531-532

ISSN : 0035-0974

Référence électronique

Valéry Pratt, « Matthias Gемӓнцісн, Frankreich und der Nürnberger Prozess gegen die

Hauptkriegsverbrecher 1945/46 ", Revue d'Allemagne et des pays de langue allemande [En ligne], 51-2 I

2019, mis en ligne le 02 décembre 2019, consulté le 25 mai 2021. URL : http://

journals.openedition.org/allemagne/2088; DOI : https://doi.org/10.4000/allemagne.2088 
Matthias GEMÄHLICH, Frankreich und der Nürnberger Prozess gegen die Hauptkriegsverbrecher 1945/46, Berlin, Peter Lang, 2018, 391 p.

Que la France soit rappelée à sa participation au Tribunal militaire international de Nuremberg de la part d'un jeune historien allemand (dont ce livre est issu de la thèse) est tout à la fois singulier et intéressant. C'est sur cet oubli, symptomatique, que s'ouvre la présente étude: lorsque la France a ratifié le statut de Rome (de la Cour pénale internationale) le 22 février 2000, et qu'elle s'est ainsi présentée à elle-même comme pionnière dans la lutte pour une justice universelle, il n'a pas été question, ni dans la bouche des parlementaires ni dans la mémoire du gouvernement, Védrine en tête (pour les Affaires étrangères), de rappeler que la France avait été pleinement partie prenante au Procès international des "grands criminels de guerre», au même titre que les trois autres nations alliées: c'est "une forme singulière d'oubli de l'histoire» (p. 14) dont l'auteur donne d'autres exemples en ouverture. C'est qu'il y va de la conscience que ce pays a de lui-même, de sa capacité réflexive et critique, de sa Selbstverständigung en somme, comme dirait Habermas, philosophe né en 1929, qui a de son côté été si sensible à la manière dont les Alliés ont initié la reconstruction de la société allemande par cette criminalisation pénale du régime nazi à travers ses dignitaires. Il y avait vu une étape essentielle dans la dénazification et la possible démocratisation de la société allemande ravagée.

Grâce au pas de côté que nous permet de faire Matthias Gemählich, c'est justement cette Selbstverständigung qui progresse. En effet, le décentrement qu'il nous invite à opérer force le respect. L'ampleur et la précision du travail, qui combine au besoin le regard de l'historien et le questionnement du juriste, dans un souci explicite d'interdisciplinarité, la méticulosité de l'argumentation et le soin mis à parcourir les archives permettent d'entreprendre "une évaluation exhaustive du rôle de la France» (p. 17) tout au long de cet événement judiciaire qui n'est pas seulement de nature mondiale, mais aussi nationale. La méthode est celle de "l'histoire croisée», et ce dans une perspective transnationale. La période concerne aussi bien le Procès lui-même que sa préhistoire et ses conséquences. L'étude est menée en quatre parties systématiques qui visent à construire un tout.

Gemählich étudie tout d'abord "le chemin de la France vers Nuremberg» (clairement emprunté par la France libre dès la Déclaration de St James du 12 janvier 1942 grâce à un René Cassin (p. 38-40) dont le rôle est bien cerné jusqu'à sa participation en tant que délégué de la France à la Commission des crimes de guerre des Nations unies le 20 octobre 1943), soit son rôle dans l'institution du TMI: comment s'est-elle impliquée pendant la guerre dans les discussions interalliées autour de l'élaboration des instruments pénaux internationaux? Quels furent sa volonté et son désir? À l'évidence la France était très mal préparée pour convaincre qui que ce soit lors des négociations menant à l'Accord du 8 août 1945 à Londres.

Il présente ensuite la délégation française à Nuremberg, tant du côté de l'équipe des procureurs que des juges, en cherchant à mettre en évidence des éléments mal connus jusque-là: qui étaient ces 250 personnes? Comment furent-elles sélectionnées? On se souvient du procureur français en chef, de Menthon, qui pourtant n'avait pas participé aux négociations à Londres, et a fait un séjour limité à Nuremberg avant d'endosser le rôle de ministre de la Justice du Gouvernement provisoire. Mais il a tout de même réuni avec son équipe (dont les membres importants sont présentés un à un), dirigée de fait par un Dubost, dont l'auteur met en évidence qu'il était l'orateur le plus important de son pays (p. 113), 1500 documents valant officiellement pour preuve et visant à dénoncer les crimes de guerre ainsi que les crimes contre l'humanité commis à l'ouest 
de l'Europe. La France a vite pris la mesure du sens et de l'importance de l'investissement nécessaire, ayant conscience de son rôle pionnier dans la défense d'une nouvelle conception du droit international à travers la poursuite des crimes contre l'humanité, mais aussi à travers l'insistance sur l'idée de culpabilité allemande.

Le pas suivant le mène vers le cour de son travail: l'analyse de la participation de la France au cours du Procès en tant que tel (20.1 1.1945-31.08.1946), auquel l'historien consacre presque cent pages (p. 179-270). Son rôle a-t-il été aussi anecdotique qu'on a pu le dire? Quelle fut son effectivité? La France entre en scène avec le plaidoyer de De Menthon le 17 janvier 1946; jusque-là elle était absente. Dans un élan métaphysique, il vise jusqu'au "crime contre la condition humaine» (das Verbrechen gegen die Menschenwürde). C'est Dubost qui exposera la partie la plus importante du plaidoyer à partir du 24 janvier en dénonçant la politique d'atrocités menée par l'occupant dans les territoires concernés à l'encontre des civils et des prisonniers de guerre. Faure mettra la dernière touche à ces trois semaines de plaidoyer qui constituent l'apport principal de la France au Procès (p. 215). Sont également analysés les relations aux autres délégations, la confrontation à la défense ou encore les contre-interrogatoires, et le plaidoyer final. Sans oublier la procédure contre les organisations criminelles.

II conclut son travail en considérant la réception du Procès en France, tant dans l'opinion publique que dans ses conséquences politiques, puis dans notre histoire judiciaire, ce jusqu'à la poursuite des crimes contre l'humanité, dont l'imprescriptibilité sera établie en droit français en 1964.

Dans l'historiographie principale, en anglais et en allemand, ces questions n'avaient jusqu'alors jamais été traitées de front, ni en profondeur. La présence des Français et de la France était au mieux mentionnée, mais jamais approfondie comme telle. Du côté de la langue française, la presse, déjà pendant le Procès, a fourni des reportages symptomatiques; puis des publications nombreuses ont permis aux Français de lire le plaidoyer de De Menthon ou le jugement lui-même. L'auteur s'intéresse donc tant à la constitution d'une vérité historique qu'à l'édification d'un espace public démocratique dans la France libérée. Mais tout ce qui peut se lire depuis en français puise aux mêmes sources, c'est-à-dire aux textes officiels parus à la fin des années 40, comme les minutes de tout le procès. II a fallu plonger dans les archives pour renouveler la lecture de cette implication de la France. Ce qui obligeait l'historien à repérer puis trouver, et rassembler ces archives, ce qu'aucune instance officielle n'avait eu pour mission de faire, autre symptôme de ce singulier oubli de l'histoire... Travail déjà mené en partie par Antonin Tisseron qui aborde cependant, dans une thèse sous la direction d'Annette Wieviorka, le procès de Nuremberg vu de France dans l'optique plus large de l'invention du droit international. Or, ce qui intéresse Gemählich c'est bien le procès en tant que tel, et vu de France, par la France. Il a fallu trouver les documents pertinents non seulement dans les Archives diplomatiques, les Archives nationales, mais également dans les dossiers de carrière du Ministère de la Justice ou, encore, concernant de Menthon, aux Archives départementales de la Haute-Savoie. Toutes les archives ne sont pas déclassifiées et l'historien a dû obtenir parfois des autorisations spéciales.

Fort de ce travail, il peut conclure en affirmant que "la France a participé à la mise en forme du Procès contre les grands criminels de guerre et apporté une contribution propre, tout sauf symbolique, à cette procédure. Cette contribution mérite de ne pas être oubliée par la postérité» (p. 353). 